\title{
Cdc48: A Swiss Army Knife of Cell Biology
}

\author{
Guem Hee Baek, ${ }^{1}$ Haili Cheng, ${ }^{1}$ Vitnary Choe, ${ }^{1}$ Xin Bao, ${ }^{1}$ \\ Jia Shao, ${ }^{2}$ Shiwen Luo, ${ }^{2}$ and Hai Rao ${ }^{1}$ \\ ${ }^{1}$ Department of Molecular Medicine, University of Texas Health Science Center, San Antonio, TX 78229, USA \\ ${ }^{2}$ The First Affiliated Hospital, Nanchang University, Nanchang, Jiangxi 330006, China
}

Correspondence should be addressed to Shiwen Luo; shiwen1029@hotmail.com and Hai Rao; raoh@uthscsa.edu

Received 31 May 2013; Revised 29 July 2013; Accepted 12 August 2013

Academic Editor: Heather M. Wallace

Copyright (C) 2013 Guem Hee Baek et al. This is an open access article distributed under the Creative Commons Attribution License, which permits unrestricted use, distribution, and reproduction in any medium, provided the original work is properly cited.

\begin{abstract}
Cdc48 (also called VCP and p97) is an abundant protein that plays essential regulatory functions in a broad array of cellular processes. Working with various cofactors, Cdc48 utilizes its ATPase activity to promote the assembly and disassembly of protein complexes. Here, we review key biological functions and regulation of Cdc48 in ubiquitin-related events. Given the broad employment of Cdc48 in cell biology and its intimate ties to human diseases (e.g., amyotrophic lateral sclerosis), studies of Cdc48 will bring significant insights into the mechanism and function of ubiquitin in health and diseases.
\end{abstract}

\section{Introduction}

Thirty years ago when David Botstein's laboratory first isolated $c d c 48-1$ allele among 18 cold-sensitive yeast mutants defective in cell cycle progression [1], little did they know how much power is embedded in CDC48. Although Cdc48 was initially suspected to play a pivotal role in some nuclear event(s) essential for cell cycle progression, it is now known to be a key regulator for a myriad of cellular processes in nucleus, cytosol, mitochondria, peroxisome, endoplasmic reticulum (ER), Golgi, lysosome, and plasma membrane [26]. Befittingly, Cdc48 is one of the most abundant proteins in eukaryotic cells, accounting for $1 \%$ of cytosolic proteins $[5,7]$. The mammalian homologue of Cdc48 is also called p97 for molecular weight or VCP (valosin-containing protein) by the groups that identified it with different approaches in various systems $[1,8,9]$. Although little attention was paid to Cdc48 early on, its stock has risen dramatically in recent years (Figure 1).

Evolutionally conserved Cdc48 is an ATPase essential for cell growth and survival. It is a central component in many ubiquitin-mediated pathways and participates in a wide range of biological events, including cell cycle regulation, protein degradation, membrane fusion, DNA replication, gene expression, DNA damage response, apoptosis, and autophagy $[2-5,7,10,11]$. A book would be needed to comprehensively cover the various functions of Cdc48. Here, we specifically highlight a few key aspects of Cdc48: the biochemical properties, physiological regulation, and crucial biological functions.

\section{Biochemical Properties}

2.1. ATPase Activity. The biochemical basis for broad utility of Cdc48 in cell biology lies in its ATPase activity. ATPase function was first demonstrated with p97, Xenopus homologue of Cdc48 [9], and subsequently shown to be a conserved feature of $\mathrm{Cdc} 48$ homologues from yeast to human [5, 7]. Cdc48 belongs to the AAA ATPase family (ATPase associated with diverse cellular activities) that shares common structural organization and often works like chaperones $[3,6,12,13]$. Cdc48 hexamerizes into a barrelshaped structure with a central pore (Figures 2(a) and 2(b)). At its core, Cdc48 has two ATPase domains D1 and D2, both of which contain a Walker A and Walker B motif for ATP binding and hydrolysis (Figure 2(a)) $[5,7,14]$. Hexamerization of Cdc48/p97 promoted by ATP binding to D1 domain is required for its ATPase activity and biological function. During ATP hydrolysis, D2 undergoes a major structural change that could generate a pulling force to disassemble a protein complex, while D1 ring remains stable $[5,7,15]$. 


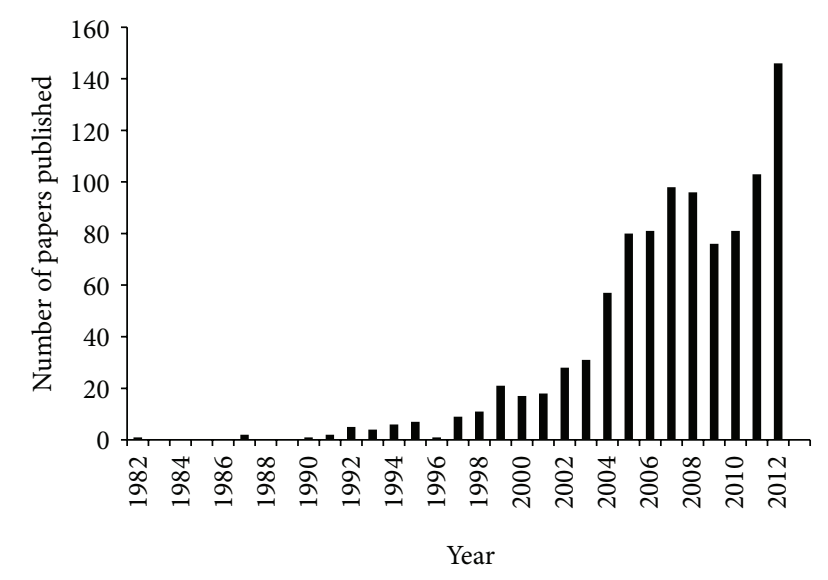

Figure 1: Number of papers on Cdc48 published since 1982. Key words "Cdc48, VCP, and p97" were used to search PUBMED for papers on Cdc48 from 1982 to 2012.

The two ends of Cdc48, the $\mathrm{N}$ domain and $\mathrm{C}$ tail, are structurally flexible and mainly involved in selecting and/or processing cargoes (Figures 2(a) and 2(b)), but they could also modulate ATPase activity via either posttranslational modification or protein-protein interaction $[2,5,15]$. Through its various cofactors and ATP activity, $\mathrm{Cdc} 48$ determines the fates of its substrates, often by extracting the client protein from its binding partners. However, it remains unresolved whether substrates are unfolded on the surface of $\mathrm{Cdc} 48$ or by threading through the central pore of $\mathrm{Cdc} 48$, like $\mathrm{ClpB}$ and GroEL ATPases $[5-7,15]$. The precise mechanism underlying the action of $\mathrm{Cdc} 48$ in diverse processes awaits further elucidation.

2.2. Ubiquitin Binding. The action of $\mathrm{Cdc} 48$ is intimately tied to ubiquitin since nearly all Cdc48-regulated events involve ubiquitin, an evolutionally conserved small protein $(\sim 8 \mathrm{kDa})$ $[3-5,11]$. Ubiquitin is often covalently attached, singly or in a chain, to lysine residues on the substrates [16, 17]. Ubiquitin is best known as a molecular flag that marks proteins for destruction by the $26 \mathrm{~S}$ proteasome but can also lead to changes in protein activity, localization, or conformation $[16,17]$.

Cdc48 was shown to directly bind ubiquitin via the $\mathrm{N}$ domain [18]. Interestingly, the ubiquitin binding was not observed in the presence of ADP, suggesting that a nucleotide-dependent conformational change may be required to expose the binding site on the $\mathrm{N}$ domain. However, the specific role and functional significance of the Cdc48ubiquitin association remain unclear, partly because more focus is placed on many Cdc 48 cofactors that exhibit stronger affinity for ubiquitin $[5,11,19,20]$. Further analysis will be required to distinguish the in vivo contribution of ubiquitinbinding activities from Cdc48 and its cofactors in specific cellular events.

Cdc48 regulates nonubiquitin related cellular events as well. Cdc48 contains a putative motif that may recognize Small Ubiquitin-like Modifier (SUMO) [21]. Although the direct binding between Cdc48 and SUMO has yet to be demonstrated, Ufd1, a Cdc 48 cofactor, can bind SUMO $[21,22]$. Interestingly, Cdc48 was recently shown to regulate SUMO-dependent processes in yeast and human via Ufd1mediated SUMO-binding [23]. Specifically Cdc48 acts as a chaperone to modulate the association of DNA repair protein Rad51 to DNA upon DNA damage [23].

2.3. Association with Diverse Cofactors. Cdc48 serves as the landing pad for its cofactors that confer substrate specificity (Figure 2(a)). If Cdc48 is regarded as a Swiss army knife of cell biology, the Cdc48-interacting cofactors $(>40)$ are then the tools (e.g., blade, corkscrew, hook, etc.) assembled in various combinations (Figure 2(c)), which allow its broad application in biology. The functional diversity of Cdc48 is achieved through its associations with an increasing number of cofactors (e.g., Ufd1-3, SVIP, Png1, and Ubx1-7), many of which also contain ubiquitin-binding motifs that allow simultaneous interactions with $\mathrm{Cdc} 48$ and ubiquitylated substrates in myriad cellular pathways $[2,5,11,19]$. Most of these cofactors possess conserved Cdc48 binding motifs such as UBX (ubiquitin regulatory $\mathrm{X}$ ), UBX-like element, BS1 sequence, VBM (VCP-binding motif), PUB, and VIM (VCP-interacting motif) $[5,11,24-26]$. Many of these cofactors are not essential for cell growth and survival, suggesting possible functional redundancy among them. Of seven UBX-containing genes identified in S. cerevisiae, yeast cells lacking any one of these UBX factors are viable, but deletions of multiple yeast UBX genes lead to severe phenotypes including cell death, suggesting that they have critical, overlapping functions $[11,24,25]$.

Most, if not all, of these cofactors are known to hang on the two ends of Cdc48, the $\mathrm{N}$ domain and $\mathrm{C}$ tail (Figures 2(a) and 2(c)). Based on their biological roles, Cdc48 cofactors are classified into two different functional groups, substraterecruiting factors and substrate-processing factors $[2,27,28]$. Whereas some of these cofactors (e.g., Ufd1 versus p47, Ufd2 versus Ufd3) compete for the docking site on Cdc48 [5, 19, 27], other cofactors can coexist in the same Cdc48 complex that likely work together to regulate specific cellular events $[5,6,11,29,30]$. For example, ubiquitin-binding proteins Ufd1 and p47 assemble distinct Cdc48 complexes. In the complex composed of Cdc48-Ufd1-Np14-Ubx2, Ubx2, an ER membrane protein is responsible for tethering the complex onto ER; Ufdl and Npl4 can recognize and present ubiquitindecorated misfolded secretory proteins for extraction out of the membrane by Cdc48 ATPase $[3,5,11]$. On the other hand, p47 and a deubiquitylating enzyme VCIP135 form another Cdc 48 complex that promotes Golgi reassembly in an ubiquitin-dependent, nonproteolytic fashion [31, 32]. Cdc48 also uses its $\mathrm{C}$ tail to form distinct complexes with ubiquitin ligase Ufd2, which promotes ubiquitin chain assembly onto the substrates, and an ubiquitin-binding protein Ufd3, which works with a deubiquitylation enzyme Otul to inhibit ubiquitin chain synthesis $[27,33,34]$. These actions suggest that Cdc48 provides a platform for two opposing activities (i.e., ubiquitylation and deubiquitylation) and thereby facilitating tight temporal and spatial control over the ubiquitylation status/fates of substrates $[5,35]$. 


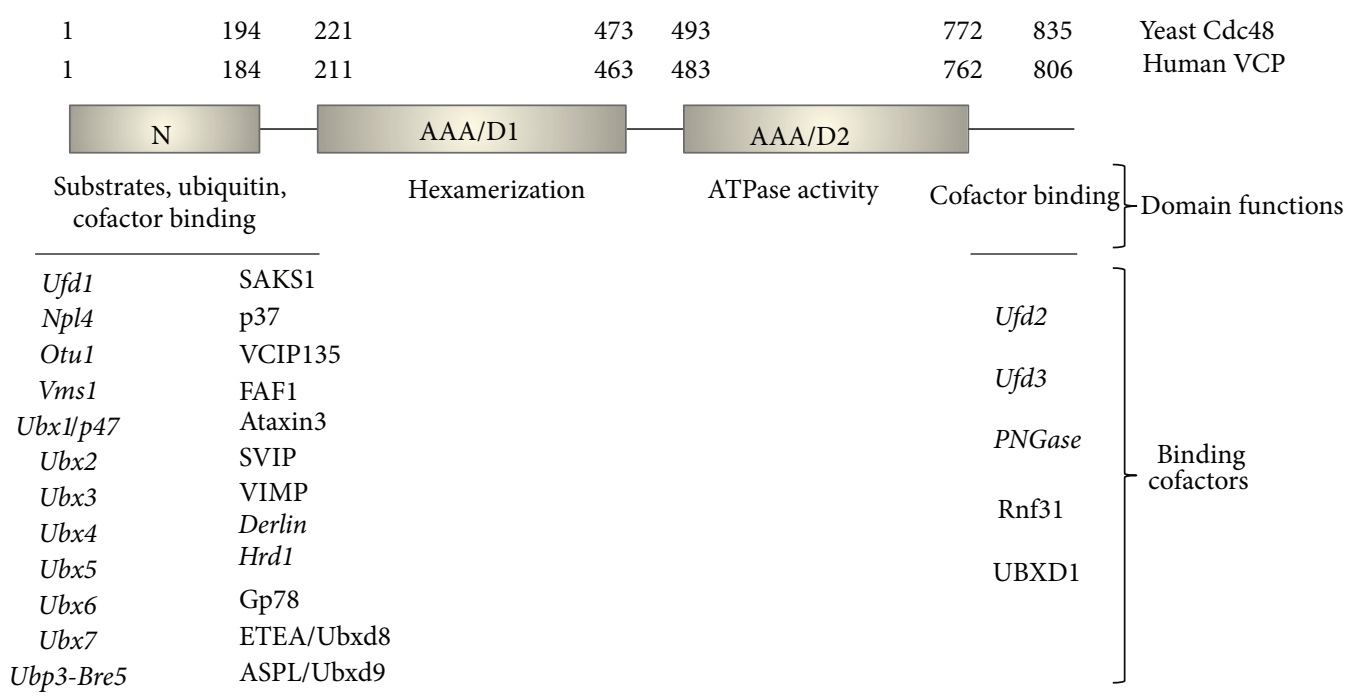

(a)

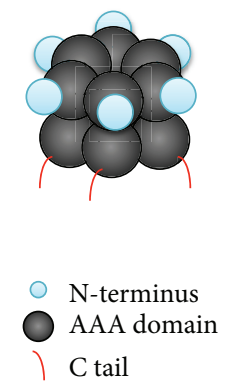

(b)

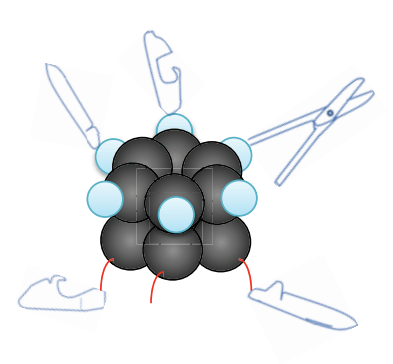

(c)

FIGURE 2: Structural and functional organization of Cdc48. (a) Cdc48 consists of the conserved N-terminal domain (N), two conserved AAA ATPase domains (D1 and D2), and the C-terminal domain (C). The numbers refer to the amino acid positions within the protein in yeast and human Cdc48, respectively. Cofactors associated with the $\mathrm{N}$ and $\mathrm{C}$ domains are listed. Yeast proteins, nearly all of which have human homologues, are highlighted in italics. (b) The active Cdc48 is a ring-shaped hexamer. (c) Cdc48 and its cofactors assemble in a Swiss army knife manner.

Since many Cdc48 cofactors have been identified and are involved in diverse processes (Table 1), it is imperative to sort out which Cdc48 cofactors coexist in one complex or are incompatible with each other and further assign specific function to each complex. Among Cdc48 cofactors, some of them known to exist in one complex are Ufd1-Npl4 and gp78 ubiquitin ligase, Png1 glycanase and gp78, FAF1 and Ufd1Npl4, Derlin and Ufd1, and Ufd1 together with Ubx2 and Ufd2. The Cdc48 cofactors that appear to be incompatible with each other include Ufd1 and p47, Ufd2 and Ufd3, Ufd1 and Vms1, SVIP and p47, SVIP and Ufd1, p37 and Ufd1, and gp78 and SVIP $[2-6,10,11]$.

\section{Regulation of Cdc48 through Posttranslational Modifications}

Despite its prevalence in cell biology, how Cdc48 activity is regulated remains poorly understood. Posttranslational modifications, such as phosphorylation and acetylation, are common mechanisms employed for controlling the way a protein behaves inside cells. For instance, the localization, enzyme activity, stability, and structure of a protein could be changed upon these modifications in response to internal or external challenges. Phosphorylation has been demonstrated to modulate the function of Cdc48 in several ways. Cdc48 can be phosphorylated at several tyrosine residues. Mammalian Cdc48 was first found to be phosphorylated at tyrosine residues 796 and 805 upon T-cell activation without affecting ATPase activity [36, 37]. Phosphorylation of corresponding residue of $\mathrm{Tyr}^{805}$ in yeast Cdc48 leads to structure alteration that allows the exposure of the $\mathrm{N}$-terminal nuclear signal, which triggers subsequent nuclear import of Cdc48 in late G1 phase of the cell cycle [38]. Phosphorylation of $\mathrm{Tyr}^{805}$, likely by v-Src kinase, completely eliminates the interaction between Cdc48 and Ufd3 or PNGase [29,39], which is involved in degradation of misfolded secretory proteins [40], further suggesting a regulatory role of phosphorylation in Cdc48's proteolytic function [39]. The action of Cdc48 in transitional ER assembly appears to be modulated by Jak2 kinase-mediated Tyr phosphorylation [41]. Dephosphorylation of Cdc48 catalyzed by PTPH1 phosphatase stabilizes 
TABLE 1: Functions and substrates of some Cdc48 cofactors.

\begin{tabular}{|c|c|c|}
\hline Cofactor & Function & Substrates \\
\hline Ufd1-Npl4 & $\begin{array}{l}\text { ERAD, cell cycle control, nuclear transport, DNA } \\
\text { repair, transcription, ribosome-associated degradation, } \\
\text { essential for cell growth, clearance of damaged } \\
\text { mitochondria }\end{array}$ & $\begin{array}{l}\text { Spt23, Mga2, Sec23, Mps1, Ole1, Hmg2, CPY* } \text { CT }^{*} \text {, } \\
\text { CTG }^{*}, \text { Ste6 }^{*}, \text { Pex29, Rad52, Rpb1, Mat } \alpha 2 \text {, Gnd1 }{ }^{\text {PTC }} \text {, } \\
\text { GFH }{ }^{\text {NS }} \text {, Fbp1, UFD model substrates, Ci/Gli3, CD } 3 \delta \text {, } \\
\text { CD4, TCR } \alpha, \text { HO-1, CDT1, SET8, tyrosinase mutant, } \\
\text { L3MBTL1, SKP2, MHC class I heavy chains, inositol 1, } \\
\text { 4,5-triphosphate receptors, Hmg-CoA reductase... }\end{array}$ \\
\hline $\mathrm{Ufd} 2 / \mathrm{E} 4 \mathrm{~B}$ & $\begin{array}{l}\text { Ubiquitin chain synthesis, cell cycle control, ERAD, } \\
\text { cardiac development, and nervous system maintenance }\end{array}$ & $\begin{array}{l}\text { Mps1, Pex29, Ste6*, Hmg2, Spt23, Fad3, UFD model } \\
\text { substrates, p53, p73, Ataxin-3, Fez1, myosin chaperone } \\
\text { UNC-45 }\end{array}$ \\
\hline Ufd3/PLAA & $\begin{array}{l}\text { Ubiquitin homeostasis, ribophagy, tRNA import to } \\
\text { mitochondria, DNA repair, multivesicular body sorting }\end{array}$ & $\begin{array}{l}\text { Cse4, Rpl25, Spt23, Cps1, Vph1, Fad3, UFD model } \\
\text { substrates, PCNA, histone H2B, N-end rule }\end{array}$ \\
\hline Vms1/ANKZF-1 & ERAD, mitochondria stress response & Cdc13, Fzo1, CFTR, CPY* \\
\hline Ubx1/p47/Shp1 & $\begin{array}{l}\text { Autophagy, nuclear envelop formation, ER biogenesis, } \\
\text { Golgi assembly }\end{array}$ & $\begin{array}{l}\text { GFP-Osh1, Fad3, UFD model substrates, NEMO, } \\
\text { Rum1 }\end{array}$ \\
\hline Ubx2 & ERAD, lipid droplet maintenance & $\begin{array}{l}\text { Hmg2, CPY* }{ }^{*} \text { KSS, Ubc6* }{ }^{*} \text {, Sec61-2, Deg1-GFP, Spt23, } \\
\text { SREBP, RNA binding protein HuR, Insig-1, ApoB-100, } \\
\text { UBC6-B5 mutant }\end{array}$ \\
\hline Ubx3 & Unknown & Unknown \\
\hline Ubx 4 & ERAD, DNA repair & CPY $^{*}$, Ste6 $^{*}$, Fbp1, Rpb1 \\
\hline Ubx5 & Links Cdc48 to CRL E3 ligases & Rpb1, HIF1 $\alpha$ \\
\hline Ubx6 & Unknown & Unknown \\
\hline Ubx7 & Unknown, in complex with $\mathrm{Dfm} 1$ & Unknown \\
\hline FAF1 & ERAD, proapoptosis factor & $\mathrm{CD} 3 \delta$, Hsp70, $\beta$-catenin \\
\hline Ataxin-3 & Ubiquitin chain editing, ERAD, stress response & $\begin{array}{l}\text { TCR } \alpha \text {, BACE mutant, SOD1, PARKIN, CHIP, integrin } \\
\text { subunits, UFD model substrates }\end{array}$ \\
\hline
\end{tabular}

Substrates of Cdc48 cofactors in yeast S. cerevisiae are indicated in bold.

the Cdc48-ER membrane association, thereby promoting ER transitional assembly [41]. Furthermore, in human U937 myeloid leukemia cells, a Tyr phosphorylated Cdc48 species is preferentially accumulated in the cytosol upon release from growth arrest, suggesting a possible role of Cdc48 in leukemic differentiation process [42].

Phosphorylation on serine and threonine residues could also regulate Cdc48 function [43]. Upon DNA damage, Cdc48 is phosphorylated at $\mathrm{Ser}^{784}$ by DNA-PK and accumulates at sites of DNA lesion [44], suggesting that $\mathrm{Ser}^{784}$ may be the key to DNA damage-triggered signaling. Under sustained hypoxia in PC-12 cells, Akt kinase can phosphorylate Cdc48 on $\mathrm{Ser}^{352}, \mathrm{Ser}^{746}$, and $\mathrm{Ser}^{748}$ [45], which leads to markedly reduced association between Cdc48 and ubiquitylated protein. Furthermore, the phosphomimetic form of Cdc48 on $\mathrm{Thr}^{761}$ exhibits elevated ATPase activity [46].

Besides phosphorylation, acetylation has been detected at several sites of Cdc48 and can affect its ATPase activity [43, 46]. Cdc48 was also shown to be S-nitrosylated at three sites (i.e., Cys110, Cys526, and Cys664) or methylated at Lys315, which inhibit its ATPase activity [47, 48]. Cdc48 may be decorated with SUMO [49] and ubiquitin [50]. However, the biological functions and significance of these modifications remain to be established. Unraveling the structural and functional consequences of these modifications on $\mathrm{Cdc} 48$ will be an important step in elucidating the mechanisms that allow the multifunctional usages of Cdc48.

\section{Biological Functions}

Cdc48 plays essential roles in cell growth and survival as demonstrated by phenotypes associated with yeast $C D C 48$ mutants and targeted deletion of mouse Cdc48 [1, 6, 51]. Consistent with its broad cellular distribution and abundance, Cdc48 regulates a myriad of physiological events (Table 1), which have been recently covered by excellent reviews $[3-5,10,11]$. For example, Drs. Dantuma and Hoppe discussed growing evidence and recognition that $\mathrm{Cdc} 48$ can act as a segregase in ubiquitin-dependent, but nonproteolytic fashion [3], supported by the reports showing that ubiquitin attachment onto ER-localized Spt23 [52], nuclear transcription factor Mata2 [53], or RNA polymerase subunit Rpb1 [54] attracts Cdc48 to release them from their sites (e.g., ER membrane, chromatin, and binding partner), which is pivotal for gene expression or DNA repair. Here we focus on three Cdc48-regulated processes, the Ubiquitin Fusion Degradation (UFD) pathway that was the first proteolytic route linked to $\mathrm{Cdc} 48$, endoplasmic reticulum associated degradation (ERAD) in which Cdc48's function is probably best characterized, and autophagy in which an understanding of Cdc48's involvement is just emerging.

4.1. The Ubiquitin Fusion Degradation (UFD) Pathway. The first indication that $\mathrm{Cdc} 48$ promotes substrate proteolysis came from its interaction with Ufd3 [66], which was initially 
isolated in a screen for genes that were required for the turnover of artificially designed UFD substrates (e.g., UbPro- $\beta$ gal, $\mathrm{Ub}^{\mathrm{V} 76}$-Val- $\beta$ gal, and $\mathrm{Ub}^{\mathrm{V} 76}$-Val-DHFR), in which the N-terminal appendage of ubiquitin targets the reporter proteins (e.g., $\beta$ gal, DHFR) for destruction by the ubiquitinproteasome system [67]. Due to the scarcity of in vivo substrates of the ubiquitin pathway in earlier days, the studies of synthetic substrates, such as UFD and N-end rule substrates, were instrumental in uncovering many key mechanistic insights about ubiquitin-mediated proteolysis $[68,69]$. The genetic dissection of the involved degradation pathways illuminated many ubiquitylation and postubiquitylation events [67-69], including the isolation of first E2 and E3 enzymes (i.e. Rad6 and Ubrl) and the first E4 enzyme (i.e., Ufd2) [70]. The early evidence for the involvement of Ufd1, Rad23, Dsk2, Cdc31, and Rad4 in proteolysis came from the work on the UFD pathway $[66,67,71]$. Importantly, these factors were later shown to be involved in many crucial cellular processes in vivo, and physiological UFD substrates (e.g., Ubb+1) have been identified, validating the employment of these model substrates $[68,69,72,73]$.

Cdc48 plays several distinct roles in the UFD pathway. One function of Cdc48 is to promote substrate ubiquitylation $[34,70,74]$. UFD substrates (e.g., $\mathrm{Ub}^{\mathrm{V} 76}$-Val- $\beta$ gal) are first decorated with a few ubiquitin molecules, which is insufficient to trigger degradation, by Ufd4 E3 ligase along with ubiquitin-activating and -conjugating enzymes (i.e., E1, E2) [70]. Oligoubiquitylated UFD substrates are then recognized by the Cdc48-Ufd1-Npl4 complex, which brings along Ufd2, a ubiquitin chain elongation factor (E4), to specifically promote ubiquitin chain extension onto UFD substrates (see the model in [74]). This assistance of Cdc48 on Ufd2's substrate recognition is supported by the disruption of in vivo Ufd2substrate association in temperature sensitive cells bearing npl4 or ufd1 mutations [74]. The requirement of Cdc48's ATPase activity for this step remains to be determined.

Another function of $\mathrm{Cdc} 48$ is after ubiquitylation to promote subsequent transfer of ubiquitylated UFD substrates to the proteasome for destruction. In vivo studies suggest that Cdc48 may also act downstream of the ubiquitylation reaction by Ufd2, as stabilized UFD substrates are ubiquitylated in $c d c 48$ and $u f d 1$ mutants $[34,70]$. One postubiquitylation event that is under the control of Cdc48 is the interaction between Ufd 2 and $\operatorname{Rad} 23$ [34]. With its abilities to bind to ubiquitin chain and the proteasome using two separate domains (i.e., UBA, UBL), $\operatorname{Rad} 23$ is a key molecule in bringing ubiquitylated proteins to the proteasome [16]. $\operatorname{Rad} 23$ is recruited to the ubiquitylation machinery via its binding to Ufd2, which in turn facilitates target recognition by the UBA domain of $\operatorname{Rad} 23$ (see the model in [34]). Through its association with Ufd2, Cdc48 uses its ATPase activity to promote the disengagement of Ufd2 and Rad23, which allows the release of substrate loaded $\operatorname{Rad} 23$ from Ufd 2 and thereby facilitating an orderly handoff of the substrate from the ubiquitylation machinery to the proteasome [34].

Studies of several synthetic UFD substrates (e.g., $\mathrm{Ub}^{\mathrm{V} 76}$-GFP, $\mathrm{Ub}^{\mathrm{V} 76}$-DHFR) also revealed that $\mathrm{Cdc} 48$ has other Ufd2-independent role(s) in the UFD pathway.
The Cdc48-Ufd1-Npl4 complex is proposed to use its ATPase activity to unfold tightly packed substrates, which may be challenging and time consuming for proteasome processing. Requirement of Cdc48 can be relieved for well-folded UFD substrates if they contain a sufficiently long ( $>20$ amino acids), flexible element [75], which is necessary for subsequent proteasome engagement.

Although Cdc48 was first found to associate with Ufd3 [66], the specific role of this interaction in the UFD pathway remains unclear. The original isolation of $u f d 3$ mutant in the screen for UFD regulators was due to the depletion of free ubiquitin in cells lacking UFD3, which affects global proteolysis and could be rescued by enhanced ubiquitin expression. Ufd3 also cooperates with a deubiquitylating enzyme Otul and competes with Ufd 2 for Cdc48 binding, which antagonizes Ufd2-catalyzed ubiquitylation reaction [27].

\subsection{Endoplasmic Reticulum Associated Degradation (ERAD).} The most extensively characterized function of Cdc48 is its pivotal roles in ERAD $[5,76,77]$, a protein quality control process, the significance of which has been increasingly appreciated owing to its emerging, prominent role in human diseases including cancer, Alzheimer's disease, diabetes, and lung emphysema. About one-third of cellular proteins travel through the ER, the folding state of secretory proteins is under stringent surveillance in the ER to ensure their quality [5, 77]. Only properly folded proteins move on to their destination to carry out their cellular functions. Immature proteins are retained in the ER for folding by ER chaperones. To prevent deleterious effects of the accumulation/aggregation of aberrant proteins, terminally misfolded proteins are destroyed via ERAD. More specifically, these unwanted proteins are ejected to the cytosol by an unknown retro-translocation mechanism. Then, the substrates are recognized by ubiquitin ligases that tag the clients with ubiquitin molecules. The ubiquitylated substrates are subsequently escorted to and degraded by the proteasome. ERAD substrates include HMG-CoA reductase, T-cell receptor $\alpha$ chain, antitrypsin, cystic fibrosis transmembrane regulator, and apolipoprotein $\mathrm{B}[5,77]$.

Based on the location of the misfolded domain (e.g., membrane, lumen, or cytosol) and the topology of the protein, ERAD substrates are sorted into different degradation pathways defined by distinct ubiquitin ligases (e.g., Hrd1, Doa10, and gp78) [5, 77-79]. And yet these pathways seem to converge on Cdc48 for the final leg of the journey to the proteasome $[5,77]$. Like its involvement in the UFD pathway, Cdc48 exerts power over multiple events in ERAD at stages pre- and postsubstrate ubiquitylation.

Cytosolic Cdc48 is tethered to the ER through the tight association with its cofactors (e.g., Ubx2, VIMP) embedded in the ER membrane, which facilitates the incorporation of Cdc48 into the protein network designed for highly coordinated ERAD $[5,77,80]$. Two Cdc 48 cofactors gp78 and Ufd 2 are ubiquitin ligases, which decorate their cargoes with ubiquitin and are part of this ensemble that selects misfolded ER proteins for destruction by the proteasome.

Cdc48 works on both nonubiquitylated and ubiquitylated ERAD targets $[20,81]$. In $c d c 48$ mutant, ERAD substrates 
are not ubiquitylated [81], suggesting that Cdc48 may be required for ubiquitylation albeit the precise function of Cdc48 remains elusive. As misfolded proteins emerge from the ER, they are recognized by ER resident E3 ubiquitin ligases such as gp78, Doa10, and Hrd1. Cdc48 binds to these ERAD substrates $[20,82]$. With its ability to differentiate the native versus nonnative state of a protein [83], Cdc48 could act as a chaperone in holding misfolded substrates exposed to an entirely new environment (i.e., cytosol), which in turn could prevent substrate backtrack and/or protein aggregation, in a state ready for ubiquitylation and degradation.

Unlike many degradation targets, ubiquitylated ERAD substrates then face a physical barrier (i.e., the ER membrane) that substrates need to traverse to reach the proteasome in the cytosol. Cdc48 ATPase plays an essential role in the dislodgement of misfolded proteins from the ER membrane by providing the power for the energy-demanding substrate retrotranslocation $[5,76,77]$. ERAD substrates remained in the ER membrane in $c d c 48$ mutants [81]. Armed with two ubiquitin binding cofactors Npl4 and Ufd1, Cdc48 is locked onto ubiquitylated cargoes $[5,19]$. The ubiquitin binding may also send a signal to Cdc48 to pull substrates out of the ER, which requires the energy derived from ATP hydrolysis by Cdc48 [5, 77, 81].

Substrates extracted by Cdc48 may take different routes to the proteasome. The precise understanding of underlying pathway selection remains murky but is likely dependent on different features such as ubiquitin chain length/linkage involved, folding status, cargo size, and the presence of sugar chains. For example, a short ubiquitin chain assembled on substrates may be further extended by Cdc 48 associated with Ufd2 ubiquitin chain elongation factor E4 [70, 74], which then shuttles cargoes to the proteasome through the Ufd2$\operatorname{Rad} 23$ connection $[40,74,84]$. Some glycoproteins may first need to be stripped off their sugar chains, which could be too bulky for the entry of the proteasome, by $\mathrm{N}$-glycanase Png1, another Cdc48 cofactor [29, 40]. Some substrates may be quickly loaded onto the proteasome that is closely tied to Cdc48 or the ER membrane [5]. Cdc48 is also found to associate with deubiquitinating enzymes (e.g., Otul), which may rescue or remodel some substrates through ubiquitin chain editing [27, 35].

Although clearly Cdc48 is central in coordinating retrotranslocation, ubiquitylation, and degradation of ERAD substrates, our understanding of Cdc48's precise role in conducting this cellular symphony remains sketchy. For example, how does Cdc48 partner with these many distinct cofactors? Do these cofactors cycle on and off Cdc48 or do different Cdc48 ensembles form a relay? How do Cdc48 and its cofactors respond to different cellular signals? How does Cdc48 work with a variety of proteins to coordinate various upstream and downstream events together?

4.3. Autophagy. The discovery of Cdc48 as a causative factor for Paget's disease of bone $[85,86]$, a degenerative disorder associated with compromised autophagy, first revealed Cdc48 as a key regulator of autophagy, another major proteolytic system in eukaryotes $[87,88]$. Autophagy has historically been deemed as a nonspecific degradation process that eliminates proteins and organelles in bulk by the lysosome to provide cellular nutrients in time of stresses (e.g., starvation), but it is emerging as a regulatory system that selectively destroys specific proteins such as $\alpha 1$-antitrypsin, APP/ $\beta$ amyloid, and Huntingtin, the accumulation of which would be detrimental to cells [87-89].

The common feature shared by various types of autophagy is that cytoplasmic cargoes are engulfed by the autophagosome, a double-membrane vesicle structure, and then escorted to and fused with the lysosome for elimination by resident hydrolases $[88,89]$. Over 30 autophagy-related (ATG) genes have been reported, and 15 of these are "core" components commonly required for distinct autophagic pathways. In response to different environmental stimuli, various adaptations of the core autophagy machinery allow cells to accordingly modulate cellular contents, including organelles (peroxisome, ribosome, and mitochondria) or intracellular proteins (e.g., Huntingtin, $\alpha$-synuclein) $[88,89]$.

Although only a little is known about the involvement of Cdc48 in autophagy, it appears that Cdc48 regulates multiple autophagy events, including maturation of autophagosomes, inclusion body formation, as evident by the accumulation of immature autophagic vesicles, and inclusion body myopathy in cells bearing Cdc48 pathogenic mutants [90, 91]. Cdc48 is tied to pathologic protein inclusions in several diseases associated with compromised autophagy activity, such as Lewy bodies in Parkinson disease, SOD positive inclusions in amyotrophic lateral sclerosis, and Huntingtin inclusion in Huntington disease $[4,91,92]$. Consistent with its multiple functions, Cdc48 interacts with several autophagy regulators, including a core factor Atg8/LC3, HDAC6 deacetylase, and regulators of specific autophagy branches such as the Ubp3Bre5 deubiquitylation complex in ribophagy [4].

Cdc48 is crucial to autophagosome biogenesis under starvation conditions through the direct interaction between its cofactor Ubx1 and a ubiquitin-like molecule Atg8/LC3 that is conjugated to phosphatidylethanolamine, the lipid enriched in the autophagic membranes [93]. ATG8 mutants are defective in autophagosome formation and membrane expansion. Ubxl preferentially binds lipidation induced Atg8 oligomers. The precise function of the Ubxl-Atg8 interaction remains unclear, but it is proposed to allow Cdc48 to extract Atg8 out of autophagosome membrane, which in turn promotes autophagosome enclosure. It is yet to be determined whether the ubiquitin binding and ATPase activity are essential for Cdc48's action in this process.

Cdc48 is required for ribophagy, an autophagy branch that selects ribosomal components for destruction by the lysosome in response to nutrient crisis $[4,94]$. Specifically, Cdc48 and its cofactor Ufd3 have been shown to work with the Ubp3-Bre5 deubiquitylating complex to promote the lysosome-mediated turnover of Rpl25 protein. RPL25 encodes a ribosomal subunit, which is rapidly degraded by autophagy upon starvation to allow cells to tune down protein synthesis.

Cdc48 and Ufd3 have been shown to interact with another autophagy regulator HDAC6, a cytosolic deacetylase [95-97]. HDAC6 binds to polyubiquitylated aggregates via $\mathrm{C}$-term ubiquitin binding BUZ domain and dynactin, 
a component of the dynein motor complex [98-100]. HDAC6 is thought to bring ubiquitylated substrates to inclusion bodies localized around the microtubule-organizing center via the microtubular transport system, and thereby promoting cargo transport to the autophagosome for subsequent destruction by autophagy [97]. The Cdc48-HDAC6 interaction has been proposed to facilitate the loading of cargos onto the HDAC6-dynein complex $[96,97]$.

Cdc48 also regulates mitophagy, an autophagy-mediated destruction of dysfunctional mitochondria. The mitophagy involvement of Cdc48 is deemed to be indirect so far since $\mathrm{Cdc} 48$ is required for proteasome-mediated degradation of two GTPases Mfn1 and Mfn2 mitofusin that mediate mitochondria fusion [101, 102]. Many tantalizing links between Cdc48 and mitophagy players (e.g., Parkin) exist and remain to be dissected $[4,99]$.

\section{Diseases Caused by Cdc48 Mutations}

Involvement of Cdc48 in myriad cellular processes suggests that it may be important for human health and disease $[4,6$, 103]. Indeed, consistent with its role in genome maintenance and modulation of various oncogenes and tumor suppressors (e.g., HIFla, p53, I $\kappa \mathrm{B} \alpha$, Brcal, NF $\kappa \mathrm{B}$, and NF1), Cdc48 expression and function have been tied to human malignancies including cancers of breast, liver, lung, pancreas, ovary, and colon $[6,103]$. More importantly, mutations in Cdc48 have been linked directly to neurodegenerative diseases including inclusion body myopathy associated with Paget's disease of the bone and frontotemporal dementia (IBMPFD) and amyotrophic lateral sclerosis (ALS) $[85,86,104]$.

The common pathogenic characteristics in autosomaldominant IBMPFD are the ubiquitylated inclusions in muscle, brain, and bone tissue that cause muscular dystrophy, neurodegeneration, and frequent bone fracture $[55,90]$. Currently 27 missense mutations in Cdc48 gene have been isolated from IBMPFD (e.g., I27V, R93C, R95C, R95G, G97E, P137L, R155C, R155S, R155L, R155P, G157R, R159H, R159C, L198W, I206F, A232E, T262A, N387H, A439S, and A439P) and/or ALS (R95H, I151V, R155H, R159G, R191G, R191Q, and D592N) patients worldwide including countries like China, Japan, Argentina, USA, Germany, Italy, and Australia [90, 105-108]. The majority of mutations are located on or closed to the $\mathrm{N}$ and $\mathrm{D} 1$ domains of $\mathrm{Cdc} 48$ and are impaired for autophagy and the degradation of ERAD substrates (e.g., CFTR) or other proteasomal targets (e.g., UNC-45). Other molecular defects found in IBMPFD patients include mitochondrial dysfunction, the accumulation of ubiquitylated species, and TAR DNA binding protein-43 (TDP-43), a major disease protein in frontotemporal dementia and ALS. Although IBMPFD associated mutations in Cdc48 often retain a normal hexameric oligomer, some mutations affect its ATPase activity and bindings to cofactors and/or substrates [56, 58-62]. Mutations in Cdc48 and associated biochemical defects that have been dissected are listed in Table 2. The molecular basis for IBMPFD and ALS caused by these Cdc48 mutations remains elusive. Distinct clinical features exist among different IBMPFD patients. The key to unravel the pathogenesis of these mutations is to comprehensively analyze their effects on cofactors bindings and specific substrate degradation.

\section{Perspective}

The field of ubiquitin and ubiquitin binding proteins has been evolving rapidly in recent years. Cdc48 plays a central and dynamic role in many ubiquitin-mediated events. Despite general realization of and interests in wide-ranging functions of Cdc48, we have only scratched the surface of its biological roles as evident by recent exciting discoveries of Cdc48's involvement in SUMO-dependent events [23] and in the ribosome-associated degradation (RAD) that eliminates misfolded nascent peptides $[109,110]$, which may include up to $\sim 30 \%$ of newly synthesized proteins. For most of the cofactors identified so far, the physiological role and significance of their interaction with Cdc48 are yet to be clearly defined [35 , 11]. Although Cdc48 can bind ubiquitin on its own, how this activity contributes to a specific process is little known with more focus having been placed on the ubiquitin binding properties of Cdc 48 cofactors. Also poorly characterized is Cdc48's binding to lipids [111], which may be critical to its function because $\mathrm{Cdc} 48$ is often attracted to various membranes (e.g., ER, autophagosome, Golgi, and mitochondria) decorated with lipids. Interestingly, like its archaeal counterpart, Cdc48 contains an HbYX motif that could be docked onto the core particle of the proteasome, raising an intriguing possibility that Cdc48 may cap on one end of the $20 \mathrm{~S}$ core proteasome particle and recognize and thread substrates into the proteolytic chamber for destruction [112, 113], which may be challenging to $19 \mathrm{~S}$ regulatory particles.

In spite of recent advances, we have much to learn about Cdc48. For example, how does Cdc48 juggle so many pivotal cellular events under normal and various stress conditions? Does Cdc48 participate in nonubiquitin and/or nonATPase dependent reactions? How does Cdc48 coordinate two major cellular degradation systems, the proteasome, and autophagy? How many more cofactors exist for $\mathrm{Cdc} 48$, and how are these cofactors organized into the same or different complex? Does Cdc48 modulate its own complex assembly and disassembly in response to internal and external stimuli? What are the specific functions and substrates of each Cdc48 complex? Could mutations in Cdc48 directly lead to cancer? How does Cdc48 and its cofactors work with other ubiquitin binding proteins (e.g., $\operatorname{Rad} 23$, Rpn10, p62, and Nbr1) that are involved in proteasome or autophagy-mediated pathways? Understanding these issues will undoubtedly illuminate many areas of cell biology.

The work on Cdc48 may also bring about potential therapeutic strategies for Cdc48-related diseases. The components of the ubiquitin/proteasome system are attractive drug targets, as illustrated by the efficacy of some proteasome inhibitors in the treatment of multiple myeloma and other cancers [17, 68]. Indeed, specific Cdc48 inhibitors have been developed $[114,115]$. For instance, small molecule DBeQ (N2, N4-dibenzylquinazoline-2,4-diamine) efficiently blocks multiple Cdc48-regulated processes, including autophagy 
TABLE 2: Mutations and defects in Cdc48-related diseases.

\begin{tabular}{|c|c|c|c|}
\hline Mutation & $\begin{array}{l}\text { Domain } \\
\text { located }\end{array}$ & Disease & Biochemical defects \\
\hline $\mathrm{R} 93 \mathrm{C}$ & $\mathrm{N}$ domain & IBMPFD & $\begin{array}{l}\text { Impaired degradation of ERAD substrates (e.g., CFTR, tyrosinase) }[55,56] ; \\
\text { restored the growth of yeast cdc } 48 \text { mutant at } 37^{\circ} \mathrm{C}[57] .\end{array}$ \\
\hline R95G & $\mathrm{N}$ domain & IBMPFD & $\begin{array}{l}\text { Increased bindings to Ufd1, Npl4, p47, Ataxin 3, and ubiquitylated substrates; } \\
\text { reduced bindings to Ufd2, CAV1, and UBXD1; little effects on the bindings to } \\
\text { Hrd1, Png1 [58-60]; altered response to nucleotide-triggered conformation } \\
\text { change of the N domain [61, 62]; enhanced ATPase activity and polyQ } \\
\text { aggregation; compromised degradation of the myosin chaperone UNC-45 and } \\
\text { ERAD substrates [63, 64]; impaired proteasome activity; accumulation of } \\
\text { ubiquitin conjugates and TDP-43; induced cell death }[6,63,64] \text {. }\end{array}$ \\
\hline P137L & $\mathrm{N}$ domain & IBMPFD & $\begin{array}{l}\text { Abolished bindings to Ufd1, Npl4, and p47, but still bind gp78 [60]; reduced } \\
\text { solubility and altered cellular localization; impaired ERAD }[60,64]\end{array}$ \\
\hline $\begin{array}{l}\mathrm{R} 155 \mathrm{H} \\
\text { The most prevalent } \\
\text { mutation }\end{array}$ & $\mathrm{N}$ domain & $\begin{array}{l}\text { IBMPFD and } \\
\text { ALS }\end{array}$ & $\begin{array}{l}\text { Increased bindings to Ufd1, Npl4, p47, Ataxin 3, and ubiquitylated substrates; } \\
\text { reduced bindings to Ufd2, CAV1, UBXD1; little effects on the bindings to Hrd1, } \\
\text { Png1 [58-60]; altered response to nucleotide-triggered conformation change of } \\
\text { the N domain [61, 62]; enhanced ATPase activity and polyQ aggregation; } \\
\text { compromised degradation of the myosin chaperone UNC-45; impaired ERAD, } \\
\text { autophagy, and proteasome; accumulation of ubiquitin conjugates and TDP-43; } \\
\text { induced cell death; mitochondria defects [6,63-65]. }\end{array}$ \\
\hline R155S & $\mathrm{N}$ domain & IBMPFD & Enhanced bindings to Ufd1, Npl4, p47, and Ataxin 3 [59]. \\
\hline $\mathrm{R} 155 \mathrm{C}$ & $\mathrm{N}$ domain & $\begin{array}{l}\text { IBMPFD and } \\
\text { ALS }\end{array}$ & $\begin{array}{l}\text { Increased bindings to Ufd1, Npl4, p47, Ataxin 3, and ubiquitylated substrates } \\
\text { [59]; enhanced ATPase activity and polyQ aggregation; impaired ERAD and } \\
\text { proteasome; accumulation of ubiquitin conjugates and TDP-43; induced cell } \\
\text { death; mitochondria defects [63-65]; rescued yeast cdc48 mutant [57]. }\end{array}$ \\
\hline $\mathrm{R} 155 \mathrm{P}$ & $\mathrm{N}$ domain & IBMPFD & $\begin{array}{l}\text { Increased bindings to Ufd1, Npl4, p47, and ubiquitylated substrates [59]; } \\
\text { enhanced ATPase activity and polyQ aggregation; normal hexmer formation; } \\
\text { altered conformation of the D2 ring; compromised degradation of ERAD } \\
\text { substrates [61-63]; rescued yeast cdc48 mutant [57]. }\end{array}$ \\
\hline R159G & $\mathrm{N}$ domain & ALS & Compromised degradation of ERAD substrates $[55,56,63]$. \\
\hline R191Q & N-D1 linker & $\begin{array}{l}\text { ALS and } \\
\text { IBMPFD }\end{array}$ & $\begin{array}{l}\text { Increased bindings to Ufd1, Npl4, p47, and ubiquitylated substrates [59]; } \\
\text { enhanced ATPase activity and polyQ aggregation; altered response to } \\
\text { nucleotide-triggered conformation change of the N domain [61, 62]; } \\
\text { compromised ERAD and proteasome; accumulation of TDP-43; induced cell } \\
\text { death }[63,64] \text {; mitochondria defects [65]; rescued yeast cdc48 mutant [57]. }\end{array}$ \\
\hline L198W & N-D1 linker & IBMPFD & Enhanced binding to ubiquitylated substrates; impaired ERAD $[59,60,63]$. \\
\hline $\mathrm{A} 232 \mathrm{E}$ & D1 domain & $\begin{array}{l}\text { IBMPFD and } \\
\text { ALS }\end{array}$ & $\begin{array}{l}\text { Increased bindings to Ufd1, Npl4, p47, and ubiquitylated substrates; reduced } \\
\text { bindings to CAV1, UBXD1 [58,59]; normal hexmer; altered response to } \\
\text { nucleotide-triggered conformation change of the N domain; altered } \\
\text { conformation of the D2 ring [61, 62]; enhanced ATPase activity and polyQ } \\
\text { aggregation; impaired ERAD, autophagy, and proteasome; accumulation of } \\
\text { ubiquitin conjugates and TDP-43; induced cell death [63]; rescued yeast cdc48 } \\
\text { mutant [57]. }\end{array}$ \\
\hline T262A & D1 domain & IBMPFD & Impaired degradation of ERAD substrates $[55,56,63]$. \\
\hline $\mathrm{N} 387 \mathrm{H}$ & D1 domain & IBMPFD & Compromised ERAD; accumulation of ubiquitin containing inclusion $[55,63]$. \\
\hline $\begin{array}{l}\text { I27V, R95C, R97C, R97E, } \\
\text { R155L, G157R, R159H, } \\
\text { R159C }\end{array}$ & $\mathrm{N}$ domain & IBMPFD & \\
\hline R95H, I151V & $\mathrm{N}$ domain & ALS & \\
\hline $\mathrm{I} 206 \mathrm{~F}$ & N-D1 linker & IBMPFD & \\
\hline R191G & N-D1 linker & ALS & \\
\hline A439S, A439P & D1 domain & IBMPFD & \\
\hline D592N & D2 domain & ALS & \\
\hline
\end{tabular}


and proteasome-mediated degradation of UFD and ERAD substrates [116]. Furthermore, DBeQ rapidly activates apoptotic cell death and inhibits cancer cell growth $[115,116]$. Other potent Cdc48 inhibitors include Eeyarestatin I [114], alkylsufanyl-1,2,4-triazoles, and sorafenib [115, 117]. Similar to proteasome inhibitor Bortezomib, these inhibitors exhibit anticancer activity. Since Cdc48 regulates a subset of proteolysis, Cdc48 related drugs may have less side effects than the proteasome inhibitors. With its ever-expanding utility, the stock of Cdc48 is sure to continue its rise in the coming years.

\section{Acknowledgments}

Hai Rao and Shiwen Luo are supported by the NIH (GM 078085, P30 CA054174), the Welch Foundation (AQ1747), the Department of Defense (W911NF-11-10466), NSFC (81060095), 973 Program of China (2010CB535001), and 555 Program of Jiangxi.

\section{References}

[1] D. Moir, S. E. Stewart, B. C. Osmond, and D. Botstein, "Coldsensitive cell-division-cycle mutants of yeast: isolation, properties, and pseudoreversion studies," Genetics, vol. 100, no. 4, pp. 547-563, 1982.

[2] S. Jentsch and S. Rumpf, "Cdc48 (p97): a "molecular gearbox" in the ubiquitin pathway?" Trends in Biochemical Sciences, vol. 32, no. 1, pp. 6-11, 2007.

[3] N. P. Dantuma and T. Hoppe, "Growing sphere of influence: Cdc48/p97 orchestrates ubiquitin-dependent extraction from chromatin," Trends in Cell Biology, vol. 22, no. 9, pp. 483-491, 2012.

[4] C. Dargemont and B. Ossareh-Nazari, “Cdc48/p97, a key actor in the interplay between autophagy and ubiquitin/proteasome catabolic pathways," Biochimica et Biophysica Acta, vol. 1823, no. 1, pp. 138-144, 2012.

[5] D. H. Wolf and A. Stolz, "The Cdc48 machine in endoplasmic reticulum associated protein degradation," Biochimica et Biophysica Acta, vol. 1823, no. 1, pp. 117-124, 2012.

[6] H. Meyer, M. Bug, and S. Bremer, "Emerging functions of the VCP/p97 AAA-ATPase in the ubiquitin system," Nature Cell Biology, vol. 14, no. 2, pp. 117-123, 2012.

[7] Y. Ye, "Diverse functions with a common regulator: ubiquitin takes command of an AAA ATPase," Journal of Structural Biolo$g y$, vol. 156, no. 1, pp. 29-40, 2006.

[8] K. J. Koller and M. J. Brownstein, "Use of a cDNA clone to identify a supposed precursor protein containing valosin," Nature, vol. 325, no. 6104, pp. 542-545, 1987.

[9] J.-M. Peters, M. J. Walsh, and W. W. Franke, "An abundant and ubiquitous homo-oligomeric ring-shaped ATPase particle related to the putative vesicle fusion proteins Sec18p and NSF," EMBO Journal, vol. 9, no. 6, pp. 1757-1767, 1990.

[10] H. N. Ramanathan and Y. Ye, "Revoking the cellular license to replicate: yet another AAA assignment," Molecular Cell, vol. 44, no. 1, pp. 3-4, 2011.

[11] A. Buchberger, "Roles of cdc48 in regulated protein degradation in yeast," Subcellular Biochemistry, vol. 66, pp. 195-222, 2013.

[12] T. Rowe and W. E. Balch, "Membrane fusion: bridging the gap by AAA ATPases,” Nature, vol. 388, no. 6637, pp. 20-21, 1997.
[13] S. Dalal and P. I. Hanson, "Membrane traffic: what drives the AAA motor?" Cell, vol. 104, no. 1, pp. 5-8, 2001.

[14] T. Ogura and A. J. Wilkinson, "AAA+ superfamily ATPases: common structure-diverse function," Genes to Cells, vol. 6, no. 7, pp. 575-597, 2001.

[15] Q. Wang, C. Song, and C.-C. H. Li, "Molecular perspectives on p97-VCP: progress in understanding its structure and diverse biological functions," Journal of Structural Biology, vol. 146, no. 1-2, pp. 44-57, 2004.

[16] D. Finley, H. D. Ulrich, T. Sommer, and P. Kaiser, “The ubiquitin-proteasome system of Saccharomyces cerevisiae," Genetics, vol. 192, no. 2, pp. 319-360, 2012.

[17] D. Komander and M. Rape, "The ubiquitin code," Annual Review of Biochemistry, vol. 81, pp. 203-229, 2012.

[18] R. M. Dai and C.-C. H. Li, "Valosin-containing protein is a multi-ubiquitin chain-targeting factor required in ubiquitinproteasome degradation," Nature Cell Biology, vol. 3, no. 8, pp. 740-744, 2001.

[19] H. H. Meyer, Y. Wang, and G. Warren, "Direct binding of ubiquitin conjugates by the mammalian $\mathrm{p} 97$ adaptor complexes, p47 and Ufd1-Npl4," EMBO Journal, vol. 21, no. 21, pp. 5645-5652, 2002.

[20] Y. Ye, H. H. Meyer, and T. A. Rapoport, "Function of the p97-Ufd1-Npl4 complex in retrotranslocation from the ER to the cytosol: dual recognition of nonubiquitinated polypeptide segments and polyubiquitin chains," Journal of Cell Biology, vol. 162, no. 1, pp. 71-84, 2003.

[21] J. T. Hannich, A. Lewis, M. B. Kroetz et al., "Defining the SUMO-modified proteome by multiple approaches in Saccharomyces cerevisiae," Journal of Biological Chemistry, vol. 280, no. 6, pp. 4102-4110, 2005.

[22] M. Nie, A. Aslanian, J. Prudden et al., "Dual recruitment of Cdc48 (p97)-Ufd1-Np14 ubiquitin-selective segregase by small ubiquitin-like modifier protein (SUMO) and ubiquitin in SUMO-targeted ubiquitin ligase-mediated genome stability functions," Journal of Biological Chemistry, vol. 287, no. 35, pp. 29610-29619, 2012.

[23] S. Bergink, T. Ammon, M. Kern, L. Schermelleh, H. Leonhardt, and S. Jentsch, "Role of Cdc48/p97 as a SUMO-targeted segregase curbing Rad51-Rad52 interaction," Nature Cell Biology, vol. 15 , no. 5, pp. 526-532, 2013.

[24] A. Decottignies, A. Evain, and M. Ghislain, "Binding of Cdc48p to a ubiquitin-related UBX domain from novel yeast proteins involved in intracellular proteolysis and sporulation," Yeast, vol. 21, no. 2, pp. 127-139, 2004.

[25] C. Schuberth, H. Richly, S. Rumpf, and A. Buchberger, "Shp1 and Ubx2 are adaptors of Cdc48 involved in ubiquitindependent protein degradation," EMBO Reports, vol. 5, no. 8, pp. 818-824, 2004.

[26] L. Madsen, M. Seeger, C. A. Semple, and R. Hartmann-Petersen, "New ATPase regulators-p97 goes to the PUB," International Journal of Biochemistry and Cell Biology, vol. 41, no. 12, pp. 23802388, 2009.

[27] S. Rumpf and S. Jentsch, "Functional division of substrate processing cofactors of the ubiquitin-selective Cdc48 chaperone," Molecular Cell, vol. 21, no. 2, pp. 261-269, 2006.

[28] C. Schuberth and A. Buchberger, "UBX domain proteins: major regulators of the AAA ATPase Cdc48/p97," Cellular and Molecular Life Sciences, vol. 65, no. 15, pp. 2360-2371, 2008.

[29] G. Zhao, X. Zhou, L. Wang, G. Li, H. Schindelin, and W. J. Lennarz, "Studies on peptide: N-glycanase-p97 interaction 
suggest that p97 phosphorylation modulates endoplasmic reticulum-associated degradation," Proceedings of the National Academy of Sciences of the United States of America, vol. 104, no. 21, pp. 8785-8790, 2007.

[30] G. Zhao, G. Li, H. Schindelin, and W. J. Lennarz, "An Armadillo motif in Ufd3 interacts with Cdc48 and is involved in ubiquitin homeostasis and protein degradation," Proceedings of the National Academy of Sciences of the United States of America, vol. 106, no. 38, pp. 16197-16202, 2009.

[31] K. Uchiyama, E. Jokitalo, F. Kano et al., "VCIP135, a novel essential factor for $\mathrm{p} 97 / \mathrm{p} 47$-mediated membrane fusion, is required for golgi and ER assembly in vivo," Journal of Cell Biology, vol. 159, no. 5, pp. 855-866, 2002.

[32] Y. Wang, A. Satoh, G. Warren, and H. H. Meyer, "VCIP135 acts as a deubiquitinating enzyme during p97-p47-mediated reassembly of mitotic Golgi fragments," Journal of Cell Biology, vol. 164, no. 7, pp. 973-978, 2004.

[33] S. Böhm, G. Lamberti, V. Fernández-Sáiz, C. Stapf, and A. Buchberger, "Cellular functions of Ufd2 and Ufd3 in proteasomal protein degradation depend on Cdc48 binding," Molecular and Cellular Biology, vol. 31, no. 7, pp. 1528-1539, 2011.

[34] G. H. Baek, I. Kim, and H. Rao, “The Cdc48 ATPase modulates the interaction between two proteolytic factors Ufd2 and Rad23," Proceedings of the National Academy of Sciences of the United States of America, vol. 108, no. 33, pp. 13558-13563, 2011.

[35] Y. Liu and Y. Ye, "Roles of p97-associated deubiquitinases in protein quality control at the endoplasmic reticulum," Current Protein \& Peptide Science, vol. 13, no. 5, pp. 436-446, 2012.

[36] M. Egerton, O. R. Ashe, D. Chen, B. J. Druker, W. H. Burgess, and L. E. Samelson, "VCP, the mammalian homolog of cdc48, is tyrosine phosphorylated in response to $\mathrm{T}$ cell antigen receptor activation," EMBO Journal, vol. 11, no. 10, pp. 3533-3540, 1992.

[37] M. Egerton and L. E. Samelson, "Biochemical characterization of valosin-containing protein, a protein tyrosine kinase substrate in hematopoietic cells," Journal of Biological Chemistry, vol. 269, no. 15, pp. 11435-11441, 1994.

[38] F. Madeo, J. Schlauer, H. Zischka, D. Mecke, and K.-U. Fröhlich, "Tyrosine phosphorylation regulates cell cycle-dependent nuclear localization of Cdc48p," Molecular Biology of the Cell, vol. 9, no. 1, pp. 131-141, 1998.

[39] G. Li, G. Zhao, H. Schindelin, and W. J. Lennarz, "Tyrosine phosphorylation of ATPase p97 regulates its activity during ERAD," Biochemical and Biophysical Research Communications, vol. 375, no. 2, pp. 247-251, 2008.

[40] I. Kim, J. Ahn, C. Liu et al., “The Pngl-Rad23 complex regulates glycoprotein turnover," Journal of Cell Biology, vol. 172, no. 2, pp. 211-219, 2006.

[41] C. Lavoie, E. Chevet, L. Roy et al., "Tyrosine phosphorylation of p97 regulates transitional endoplasmic reticulum assembly in vitro," Proceedings of the National Academy of Sciences of the United States of America, vol. 97, no. 25, pp. 13637-13642, 2000.

[42] C. Bertram, N. Von Neuhoff, B. Skawran, D. Steinemann, B. Schlegelberger, and R. Hass, "The differentiation/retrodifferentiation program of human U937 leukemia cells is accompanied by changes of VCP/p97," BMC Cell Biology, vol. 9, article 12, 2008.

[43] C. A. Ewens, P. Kloppsteck, A. Förster, X. Zhang, and P. S. Freemont, "Structural and functional implications of phosphorylation and acetylation in the regulation of the AAA+ protein p97," Biochemistry and Cell Biology, vol. 88, no. 1, pp. 41-48, 2010.
[44] M. Livingstone, H. Ruan, J. Weiner et al., "Valosin-containing protein phosphorylation at Ser784 in response to DNA damage," Cancer Research, vol. 65, no. 17, pp. 7533-7540, 2005.

[45] J. B. Klein, M. T. Barati, R. Wu et al., "Akt-mediated valosincontaining protein 97 phosphorylation regulates its association with ubiquitinated proteins," Journal of Biological Chemistry, vol. 280, no. 36, pp. 31870-31881, 2005.

[46] C. Mori-Konya, N. Kato, R. Maeda et al., "p97/valosin-containing protein (VCP) is highly modulated by phosphorylation and acetylation," Genes to Cells, vol. 14, no. 4, pp. 483-497, 2009.

[47] P. Cloutier, M. Lavallee-Adam, D. Faubert, M. Blanchette, and B. Coulombe, "A newly uncovered group of distantly related lysine methyltransferases preferentially interact with molecular chaperones to regulate their activity," PLOS Genetics, vol. 9, no. 1, Article ID e1003210, 2013.

[48] S. Kernstock, E. Davydova, M. Jakobsson et al., "Lysine methylation of VCP by a member of a novel human protein methyltransferase family," Nature Communications, vol. 3, article 1038, 2012.

[49] J. A. Wohlschlegel, E. S. Johnson, S. I. Reed, and J. R. Yates III, "Global analysis of protein sumoylation in Saccharomyces cerevisiae," Journal of Biological Chemistry, vol. 279, no. 44, pp. 45662-45668, 2004.

[50] J. Peng, D. Schwartz, J. E. Elias et al., "A proteomics approach to understanding protein ubiquitination," Nature Biotechnology, vol. 21, no. 8, pp. 921-926, 2003.

[51] J. M. M. Müller, K. Deinhardt, I. Rosewell, G. Warren, and D. T. Shima, "Targeted deletion of p97 (VCP/CDC48) in mouse results in early embryonic lethality," Biochemical and Biophysical Research Communications, vol. 354, no. 2, pp. 459-465, 2007.

[52] M. Rape, T. Hoppe, I. Gorr, M. Kalocay, H. Richly, and S. Jentsch, "Mobilization of processed, membrane-tethered SPT23 transcription factor by CDC48UFD1/NPL4, a ubiquitin-selective chaperone," Cell, vol. 107, no. 5, pp. 667-677, 2001.

[53] A. J. Wilcox and J. D. Laney, "A ubiquitin-selective AAA-ATPase mediates transcriptional switching by remodelling a repressorpromoter DNA complex," Nature Cell Biology, vol. 11, no. 12, pp. 1481-1486, 2009.

[54] R. Verma, R. Oania, R. Fang, G. T. Smith, and R. J. Deshaies, "Cdc48/p97 mediates UV-dependent turnover of RNA Pol II," Molecular Cell, vol. 41, no. 1, pp. 82-92, 2011.

[55] V. E. Kimonis, E. Fulchiero, J. Vesa, and G. Watts, "VCP disease associated with myopathy, Paget disease of bone and frontotemporal dementia: review of a unique disorder," Biochimica et Biophysica Acta, vol. 1782, no. 12, pp. 744-748, 2008.

[56] C. C. Weihl, S. Dalal, A. Pestronk, and P. I. Hanson, "Inclusion body myopathy-associated mutations in p97/VCP impair endoplasmic reticulum-associated degradation," Human Molecular Genetics, vol. 15, no. 2, pp. 189-199, 2006.

[57] T. Takata, Y. Kimura, Y. Ohnuma et al., "Rescue of growth defects of yeast cdc48 mutants by pathogenic IBMPFD-VCPs," Journal of Structural Biology, vol. 179, pp. 93-103, 2012.

[58] V. Fernández-Sáiz and A. Buchberger, "Imbalances in p97 cofactor interactions in human proteinopathy," EMBO Reports, vol. 11, no. 6, pp. 479-485, 2010.

[59] D. Ritz, M. Vuk, P. Kirchner et al., "Endolysosomal sorting of ubiquitylated caveolin-1 is regulated by VCP and UBXD1 and impaired by VCP disease mutations," Nature Cell Biology, vol. 13, no. 9, pp. 1116-1124, 2011.

[60] Y. Erzurumlu, F. A. Kose, O. Gozen, D. Gozuacik, E. A. Toth, and P. Ballar, "A unique IBMPFD-related P97/VCP mutation 
with differential binding pattern and subcellular localization," The International Journal of Biochemistry \& Cell Biology, vol. 45, no. 4, pp. 773-782, 2013.

[61] A. Nalbandian, S. Donkervoort, E. Dec et al., "The multiple faces of valosin-containing protein-associated diseases: inclusion body myopathy with Paget's disease of bone, frontotemporal dementia, and amyotrophic lateral sclerosis," Journal of Molecular Neuroscience, vol. 45, no. 3, pp. 522-531, 2011.

[62] H. Niwa, C. A. Ewens, C. Tsang, H. O. Yeung, X. Zhang, and P. S. Freemont, "The role of the $\mathrm{N}$-domain in the atpase activity of the mammalian AAA ATPase p97/VCP," Journal of Biological Chemistry, vol. 287, no. 11, pp. 8561-8570, 2012.

[63] S. G. Mehta, M. Khare, R. Ramani et al., "Genotype-phenotype studies of VCP-associated inclusion body myopathy with Paget disease of bone and/or frontotemporal dementia," Clinical Genetics, vol. 83, no. 5, pp. 422-431, 2013.

[64] A. Franz, L. Ackermann, and T. Hoppe, "Create and preserve: proteostasis in development and aging is governed by Cdc48/ p97/VCP," Biochimica et Biophysica Acta, 2013.

[65] K. Malpass, "Neurodegenerative disease: VCP mutations lead to defects in mitochondrial dynamics," Nature Reviews Neurology, vol. 9, no. 5, article 239, 2013.

[66] M. Ghislain, R. J. Dohmen, F. Levy, and A. Varshavsky, “Cdc48p interacts with Ufd3p, a WD repeat protein required for ubiquitin-mediated proteolysis in Saccharomyces cerevisiae," EMBO Journal, vol. 15, no. 18, pp. 4884-4899, 1996.

[67] E. S. Johnson, P. C. M. Ma, I. M. Ota, and A. Varshavsky, "A proteolytic pathway that recognizes ubiquitin as a degradation signal," Journal of Biological Chemistry, vol. 270, no. 29, pp. 17442-17456, 1995.

[68] A. Hershko, A. Ciechanover, and A. Varshavsky, "The ubiquitin system," Nature Medicine, vol. 6, no. 10, pp. 1073-1081, 2000.

[69] A. Varshavsky, "Discovery of cellular regulation by protein degradation," The Journal of Biological Chemistry, vol. 283, no. 50, pp. 34469-34489, 2008.

[70] M. Koegl, T. Hoppe, S. Schlenker, H. D. Ulrich, T. U. Mayer, and S. Jentsch, "A novel ubiquitination factor, E4, is involved in multiubiquitin chain assembly," Cell, vol. 96, no. 5, pp. 635-644, 1999.

[71] D. Lambertson, L. Chen, and K. Madura, "Pleiotropic defects caused by loss of the proteasome-interacting factors Rad23 and Rpn10 of Saccharomyces cerevisiae," Genetics, vol. 153, no. 1, pp. 69-79, 1999.

[72] K. Lindsten, F. M. S. De Vrij, L. G. G. C. Verhoef et al., "Mutant ubiquitin found in neurodegenerative disorders is a ubiquitin fusion degradation substrate that blocks proteasomal degradation," Journal of Cell Biology, vol. 157, no. 3, pp. 417-427, 2002.

[73] C. Liu, D. Van Dyk, P. Xu et al., "Ubiquitin chain elongation enzyme Ufd2 regulates a subset of Doal0 substrates," Journal of Biological Chemistry, vol. 285, no. 14, pp. 10265-10272, 2010.

[74] H. Richly, M. Rape, S. Braun, S. Rumpf, C. Hoege, and S. Jentsch, "A series of ubiquitin binding factors connects CDC48/p97 to substrate multiubiquitylation and proteasomal targeting," Cell, vol. 120, no. 1, pp. 73-84, 2005.

[75] L. G. G. C. Verhoef, C. Heinen, A. Selivanova, E. F. Halff, F. A. Salomons, and N. P. Dantuma, "Minimal length requirement for proteasomal degradation of ubiquitin-dependent substrates," FASEB Journal, vol. 23, no. 1, pp. 123-133, 2009.

[76] Y. Ye, H. H. Meyer, and T. A. Rapoport, "The AAA ATPase Cdc48/p97 and its partners transport proteins from the ER into the cytosol," Nature, vol. 414, no. 6864, pp. 652-656, 2001.
[77] S. S. Vembar and J. L. Brodsky, "One step at a time: endoplasmic reticulum-associated degradation," Nature Reviews Molecular Cell Biology, vol. 9, no. 12, pp. 944-957, 2008.

[78] S. Vashist and D. T. W. Ng, "Misfolded proteins are sorted by a sequential checkpoint mechanism of ER quality control," Journal of Cell Biology, vol. 165, no. 1, pp. 41-52, 2004.

[79] P. Carvalho, V. Goder, and T. A. Rapoport, "Distinct ubiquitinligase complexes define convergent pathways for the degradation of ER proteins," Cell, vol. 126, no. 2, pp. 361-373, 2006.

[80] Y. Ye, Y. Shibata, C. Yun, D. Ron, and T. A. Rapoport, "A membrane protein complex mediates retro-translocation from the ER lumen into the cytosol," Nature, vol. 429, no. 6994, pp. 841847, 2004.

[81] Y. Elkabetz, I. Shapira, E. Rabinovich, and S. Bar-Nun, "Distinct steps in dislocation of luminal endoplasmic reticulum-associated degradation substrates. Roles of endoplasmic reticulumbound p97/Cdc48p and proteasome," Journal of Biological Chemistry, vol. 279, no. 6, pp. 3980-3989, 2004.

[82] D. Flierman, Y. Ye, M. Dai, V. Chau, and T. A. Rapoport, "Polyubiquitin serves as a recognition signal, rather than a ratcheting molecule, during retrotranslocation of proteins across the endoplasmic reticulum membrane," Journal of Biological Chemistry, vol. 278, no. 37, pp. 34774-34782, 2003.

[83] S. Thoms, "Cdc48 can distinguish between native and nonnative proteins in the absence of cofactors," FEBS Letters, vol. 520, no. 1-3, pp. 107-110, 2002.

[84] I. Kim, K. Mi, and H. Rao, "Multiple interactions of Rad23 suggest a mechanism for ubiquitylated substrate delivery important in proteolysis," Molecular Biology of the Cell, vol. 15, no. 7, pp. 3357-3365, 2004.

[85] V. E. Kimonis, M. J. Kovach, B. Waggoner et al., "Clinical and molecular studies in a unique family with autosomal dominant limb-girdle muscular dystrophy and Paget disease of bone," Genetics in Medicine, vol. 2, no. 4, pp. 232-241, 2000.

[86] G. D. J. Watts, J. Wymer, M. J. Kovach et al., "Inclusion body myopathy associated with Paget disease of bone and frontotemporal dementia is caused by mutant valosin-containing protein," Nature Genetics, vol. 36, no. 4, pp. 377-381, 2004.

[87] H. Nakatogawa, K. Suzuki, Y. Kamada, and Y. Ohsumi, "Dynamics and diversity in autophagy mechanisms: lessons from yeast," Nature Reviews Molecular Cell Biology, vol. 10, no. 7, pp. 458-467, 2009.

[88] Z. Yang and D. J. Klionsky, "Eaten alive: a history of macroautophagy," Nature Cell Biology, vol. 12, no. 9, pp. 814-822, 2010.

[89] M. Komatsu and Y. Ichimura, "Selective autophagy regulates various cellular functions," Genes to Cells, vol. 15, no. 9, pp. 923933, 2010.

[90] J.-S. Ju and C. C. Weihl, "Inclusion body myopathy, Paget's disease of the bone and fronto-temporal dementia: a disorder of autophagy," Human Molecular Genetics, vol. 19, no. 1, pp. R38R45, 2010.

[91] E. Tresse, F. A. Salomons, J. Vesa et al., "VCP/p97 is essential for maturation of ubiquitin-containing autophagosomes and this function is impaired by mutations that cause IBMPFD," Autophagy, vol. 6, no. 2, pp. 217-227, 2010.

[92] S. Ishigaki, N. Hishikawa, J.-I. Niwa et al., "Physical and functional interaction between dorfin and valosin-containing protein that are colocalized in ubiquitylated inclusions in neurodegenerative disorders," Journal of Biological Chemistry, vol. 279, no. 49, pp. 51376-51385, 2004. 
[93] R. Krick, S. Bremer, E. Welter et al., "Cdc48/p97 and Shp1/p47 regulate autophagosome biogenesis in concert with ubiquitinlike Atg8," Journal of Cell Biology, vol. 190, no. 6, pp. 965-973, 2010.

[94] B. Ossareh-Nazari, M. Bonizec, M. Cohen et al., "Cdc48 and $\mathrm{Ufd} 3$, new partners of the ubiquitin protease Ubp3, are required for ribophagy," EMBO Reports, vol. 11, no. 7, pp. 548-554, 2010.

[95] D. Seigneurin-Berny, A. Verdel, S. Curtet et al., "Identification of components of the murine histone deacetylase 6 complex: link between acetylation and ubiquitination signaling pathways," Molecular and Cellular Biology, vol. 21, no. 23, pp. 8035-8044, 2001.

[96] C. Boyault, B. Gilquin, Y. Zhang et al., "HDAC6-p97/VCP controlled polyubiquitin chain turnover," EMBO Journal, vol. 25, no. 14, pp. 3357-3366, 2006.

[97] J.-Y. Lee and T.-P. Yao, "Quality control autophagy: a joint effort of ubiquitin, protein deacetylase and actin cytoskeleton," Autophagy, vol. 6, no. 4, pp. 555-557, 2010.

[98] Y. Kawaguchi, J. J. Kovacs, A. McLaurin, J. M. Vance, A. Ito, and T.-P. Yao, "The deacetylase HDAC6 regulates aggresome formation and cell viability in response to misfolded protein stress," Cell, vol. 115, no. 6, pp. 727-738, 2003.

[99] J. A. Olzmann, A. Li, M. V. Chudaev et al., "Parkin-mediated K63-linked polyubiquitination targets misfolded DJ-1 to aggresomes via binding to HDAC6," Journal of Cell Biology, vol. 178, no. 6, pp. 1025-1038, 2007.

[100] H. Ouyang, Y. O. Ali, M. Ravichandran et al., "Protein aggregates are recruited to aggresome by histone deacetylase 6 via unanchored ubiquitin C termini," Journal of Biological Chemistry, vol. 287, no. 4, pp. 2317-2327, 2012.

[101] A. Tanaka, M. M. Cleland, S. Xu et al., "Proteasome and p97 mediate mitophagy and degradation of mitofusins induced by Parkin," Journal of Cell Biology, vol. 191, no. 7, pp. 1367-1380, 2010.

[102] S. Xu, G. Peng, Y. Wang, S. Fang, and M. Karbowsk, "The AAAATPase p97 is essential for outer mitochondrial membrane protein turnover," Molecular Biology of the Cell, vol. 22, no. 3, pp. 291-300, 2011.

[103] D. S. Haines, "p97-containing complexes in proliferation control and cancer: emerging culprits or Guilt by association?" Genes and Cancer, vol. 1, no. 7, pp. 753-763, 2010.

[104] J. O. Johnson, J. Mandrioli, M. Benatar et al., "Exome sequencing reveals VCP mutations as a cause of familial ALS," Neuron, vol. 68 , no. 5, pp. 857-864, 2010.

[105] D. Haubenberger, R. E. Bittner, S. Rauch-Shorny et al., "Inclusion body myopathy and Paget disease is linked to a novel mutation in the VCP gene," Neurology, vol. 65, no. 8, pp. 13041305, 2005.

[106] L. Guyant-Maréchal, A. Laquerrière, C. Duyckaerts et al., "Valosin-containing protein gene mutations: clinical and neuropathologic features," Neurology, vol. 67, no. 4, pp. 644-651, 2006.

[107] G. D. G. Watts, D. Thomasova, S. K. Ramdeen et al., "Novel VCP mutations in inclusion body myopathy associated with Paget disease of bone and frontotemporal dementia," Clinical Genetics, vol. 72, no. 5, pp. 420-426, 2007.

[108] P. González-Pérez, E. T. Cirulli, V. E. Drory et al., "Novel mutation in VCP gene causes atypical amyotrophic lateral sclerosis," Neurology, vol. 79, no. 22, pp. 2201-2208, 2012.

[109] O. Brandman, J. Stewart-Ornstein, D. Wong et al., "A ribosomebound quality control complex triggers degradation of nascent peptides and signals translation stress," Cell, vol. 151, no. 5, pp. 1042-1054, 2012.

[110] R. Verma, R. S. Oania, N. J. Kolawa, and R. J. Deshaies, “Cdc48/ p97 promotes degradation of aberrant nascent polypeptides bound to the ribosome," eLife, vol. 2, Article ID e00308, 2013.

[111] K. Shiozawa, N. Goda, T. Shimizu et al., "The common phospholipid-binding activity of the N-terminal domains of PEX1 and VCP/p97," FEBS Journal, vol. 273, no. 21, pp. 4959-4971, 2006.

[112] D. Barthelme and R. T. Sauer, "Identification of the Cdc $48 * 20 \mathrm{~S}$ proteasome as an ancient AAA+ proteolytic machine.," Science, vol. 337, no. 6096, pp. 843-846, 2012.

[113] D. Barthelme and R. T. Barthelme DSauer, "Bipartite determinants mediate an evolutionarily conserved interaction between Cdc4 8 and the 20 S peptidase," Proceedings of the National Academy of Sciences of the United States of America, vol. 110, no. 9, pp. 3327-3332, 2013.

[114] Q. Wang, B. A. Shinkre, J.-G. Lee et al., "The ERAD inhibitor eeyarestatin $\mathrm{I}$ is a bifunctional compound with a membranebinding domain and a p97/VCP inhibitory group," PLoS ONE, vol. 5, no. 11, Article ID e15479, 2010.

[115] T.-F. Chou and R. J. Deshaies, "Development of p97 AAA ATPase inhibitors," Autophagy, vol. 7, no. 9, pp. 1091-1092, 2011.

[116] T.-F. Chou, S. J. Brown, D. Minond et al., "Reversible inhibitor of p97, DBeQ, impairs both ubiquitin-dependent and autophagic protein clearance pathways," Proceedings of the National Academy of Sciences of the United States of America, vol. 108, no. 12, pp. 4834-4839, 2011.

[117] P. Yi, A. Higa, S. Taouji et al., "Sorafenib-mediated targeting of the AAA(+) ATPase p97/VCP leads to disruption of the secretory pathway, endoplasmic reticulum stress, and hepatocellular cancer cell death," Molecular Cancer Therapeutics, vol. 11, no. 12, pp. 2610-2620, 2012. 

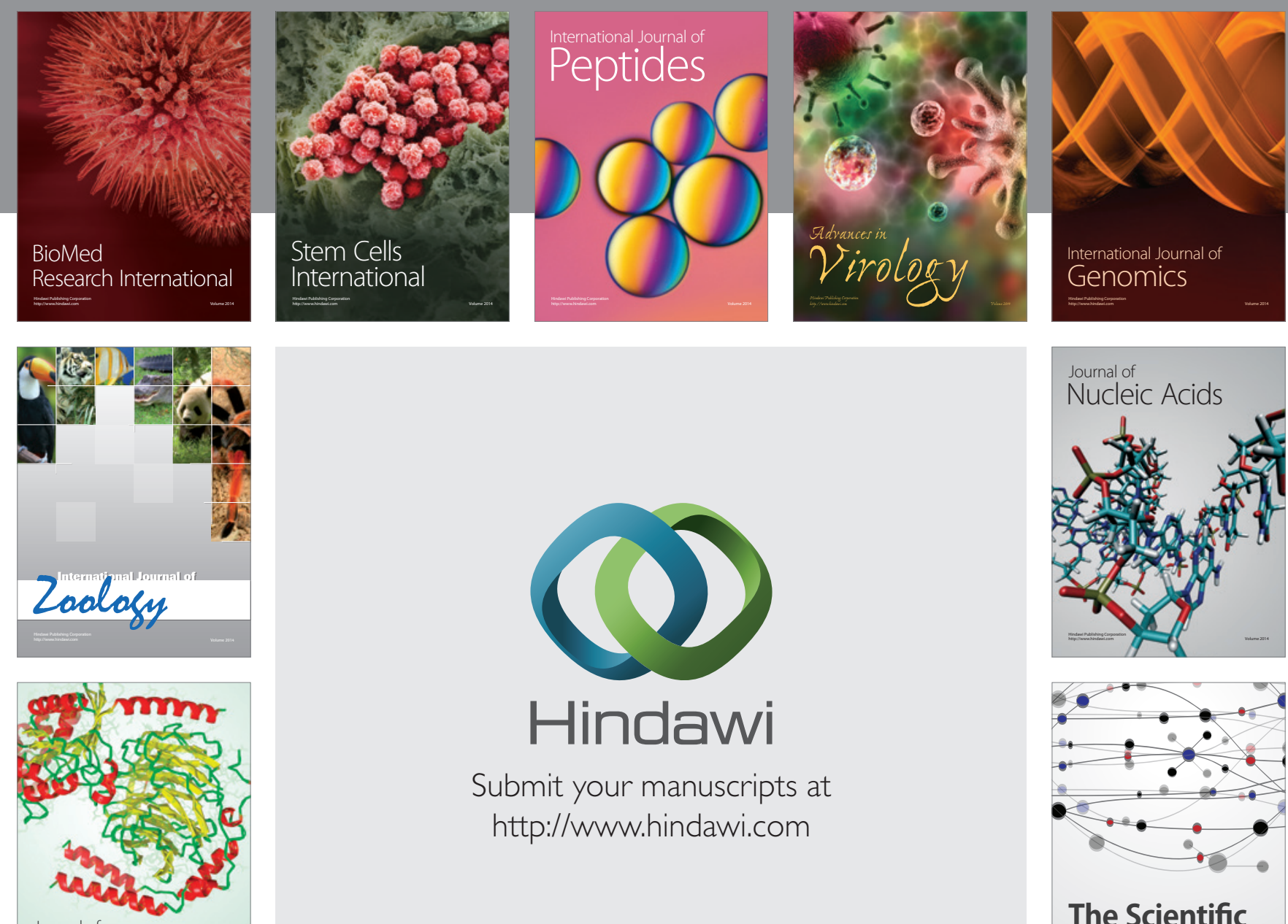

Submit your manuscripts at

http://www.hindawi.com

Journal of
Signal Transduction
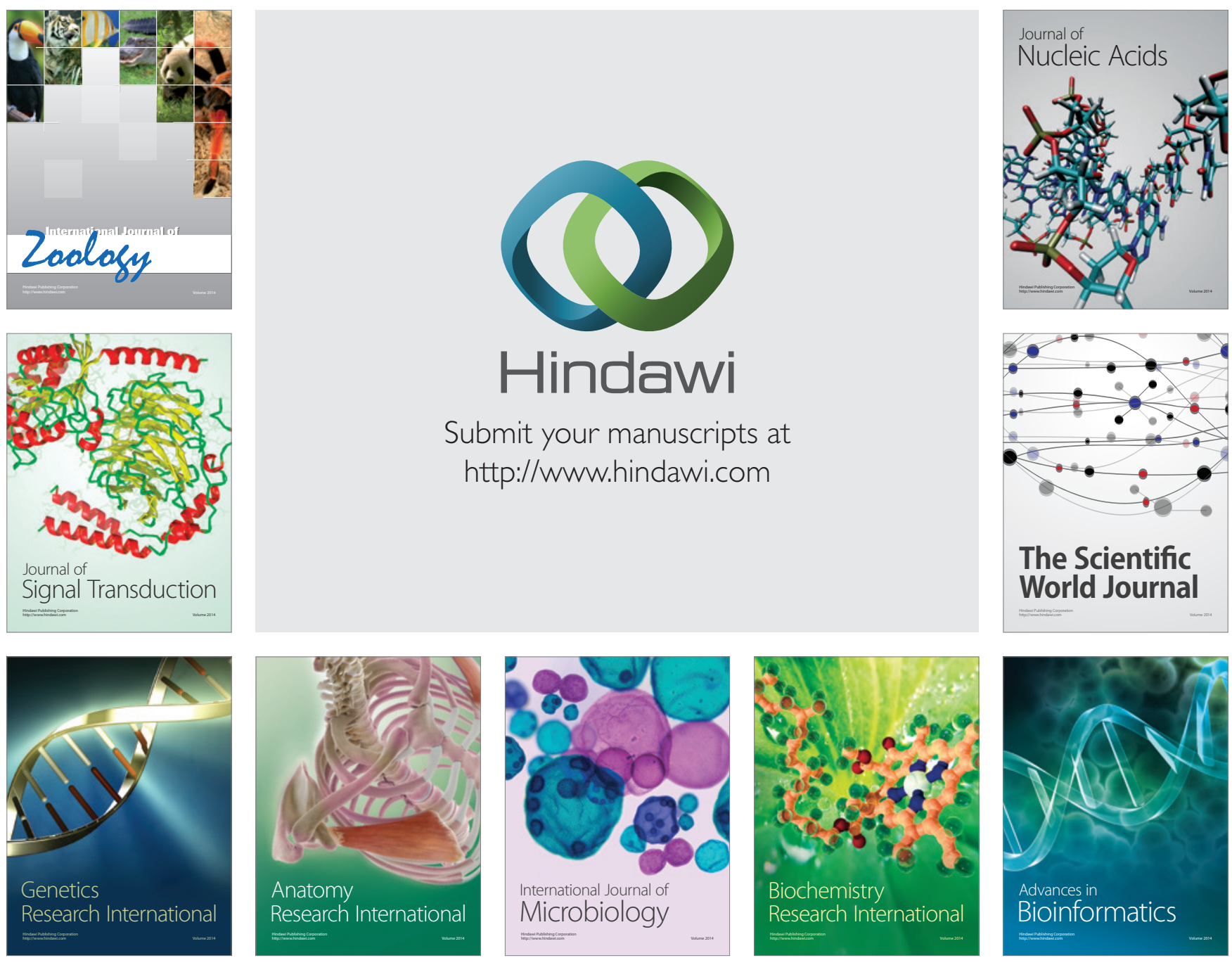

The Scientific World Journal
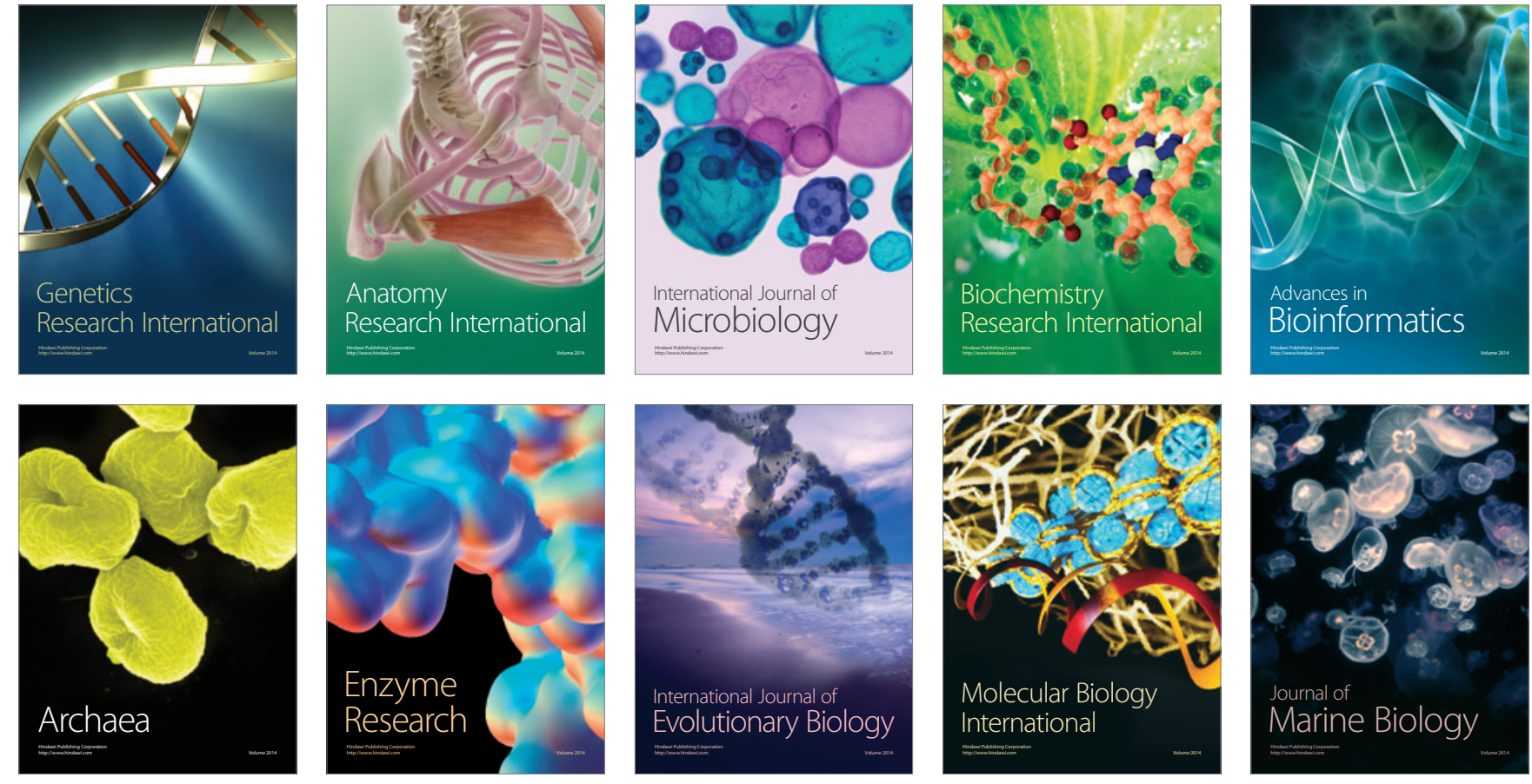